\title{
Las prácticas discursivas y gestuales: hacia una comprensión de las expresiones de poder del docente
}

\section{Discursive and gestural practices: towards an understanding of teachers' expressions of power}

Nanci Corromoto Barrios Briceño.

María del Carmen Barniol G.

Universidad de Especialidades Espíritu Santo, Ecuador

Autor para correspondencia: nbarrios@uees.edu.ec, mbarniolg@uees.ed.ec

Fecha de recepción: 02 de Agosto de 2017 - Fecha de aceptación: 10 de Agosto de 2017

Resumen: Las formas en que las ideologías se expresan y reproducen los educadores en el discurso suponen averiguar el estatuto y funciones mentales de "sus" ideologías en términos de cognición social. Las condiciones y funciones de las ideologías en el aula no sólo son cognitivas sino también sociales, políticas, culturales e históricas. Sin lugar a dudas, las ideologías se forman, cambian y se reproducen en el discurso y la comunicación socialmente situados (Van Dijk: 2000). Ahora bien, la ideología se entiende como un conjunto de ideas y representaciones que se imponen a las personas como verdades absolutas, produciendo un autoengaño, una ocultación en su pensamiento y formas de actuar; la función de las ideologías en las aulas constituyen y modelan formas bajo las cuales los alumnos viven y construyen significativamente su realidad, sus emociones, sueños, intereses y otros. Las ideologías de los educadores muchas veces traducen una visión del mundo, una perspectiva de las cosas, de los acontecimientos y comportamientos; las mismas constituyen una construcción socio histórica por lo tanto, son relativas, parciales, incompletas y requieren de reelaboraciones continuas para evitar caer en los absolutismos que no permitan la reflexión y al contrario favorezcan la dominación. La concepción del mundo que traduce la ideología dota a los educandos de un sentido de pertenencia e identidad, les hace conscientes de las posibilidades y limitaciones de sus actos.

Palabras Clave: prácticas discursivas; ideología; docencia; expresiones de poder; discurso

\begin{abstract}
The ways in which the ideologies are expressed and reproduced by the educators in the discourse supposed to find out the statute and mental functions of "their" ideologies in terms of social cognition. The conditions and functions of the ideologies in the classroom are not only cognitive but also social, political, cultural and historical. Without a doubt, ideologies are formed, changed and reproduced in the socially located discourse and communication (Van Dijk: 2000). However, ideology is understood as a set of ideas and representations that are imposed on people as absolute truths, producing self-deception, concealment in their thinking and ways of acting; The function of the ideologies in the classrooms constitute and model forms under which the students live and build significantly their reality, their emotions, dreams, interests and others. The ideologies of educators often translate a worldview, a perspective of things, events and behaviors; they constitute a historical socio-construction Therefore, they are relative, partial, and incomplete and require continuous reworkings to avoid falling in the absolutisms that do not allow the reflection and on the contrary favor the domination. The conception of the world that translates ideology gives learners a sense of belonging and identity, makes them aware of the possibilities and limitations of their actions.
\end{abstract} Key words: discursive practices; ideology; teaching; expressions of power; discourse 


\section{Introducción}

El lenguaje como fenómeno humano, está presente en todos los planos de la vida social. El aula es uno de esos espacios, donde se legitiman significados a partir del discurso. Desde el punto de vista social se dice que sólo existe todo aquello que tiene un nombre y aquello de lo que es posible hablar. El discurso refleja el sistema del pensamiento colectivo, y con él se transmite una gran parte de la forma de pensar, sentir y actuar de cada sociedad, y esa transmisión muchas veces es inconsciente y otras consciente.

Cada persona al hablar o escribir, asigna denotaciones y connotaciones distintas y especiales a las palabras, sé es capaz de construir frases y enunciados de una manera muy particular. El lenguaje es comunicación viva que abstrae de manera simbólica a una realidad concreta y es instrumento de acción sobre las personas y sobre las situaciones.

El lenguaje como competencia comunicativa no es algo mecánico sino que digiere, asimila, modela y elabora una expresión muy particular que se va dando en base a la actuación y relación con el mundo de manera activa, pues la experiencia nos abre el camino para continuar su proceso de desarrollo y madurez. De esta manera, el hablar o escribir puede ser automático, rutinario y mecanizado o bien, una creación continua donde se manifiesta la continuidad del lenguaje.

Es posible jugar con las palabras como jugamos con la plastilina, modelamos y remodelamos y volvemos a modelar hasta hallar la forma que responda a nuestra idea o a la situación del contexto, una misma frase, con las mismas sílabas y letras, está abierta a una rica gama de significados. De allí que, la creación poética y literaria ya no sólo se limita a comunicar, no queda en precisión fría de las denotaciones sino que se adelanta por el mundo interior sinuoso, enigmático e inagotable de las connotaciones. Rodríguez (2000), expone que el docente establece un nuevo mundo de relaciones que por un lado penetran hasta las profundidades del mundo sensible y por el otro se aleja de él para elevarse a las alturas etéreas del espíritu. Es aquí donde el lenguaje alcanza su máxima expresión interviniendo como una expresión cultural de una sociedad determinada.

Al igual que otras capacidades, desde el nacimiento existe una pérdida en la expresividad espontánea del niño, esto se acentúa porque las actitudes de padres y maestros reprimen y no dan oportunidad de que el niño se exprese tal y como es. Son comunes los casos en que los padres y maestros castigan al niño porque le da otros significados a las palabras, porque inventa palabras, etc. Con esto lo único que logramos es matar la espontaneidad y creatividad del niño en su competencia comunicativa. En este sentido, la escuela para el niño se convierte en un nuevo hogar donde interactúa, a través del lenguaje con nuevas personas. Durante este tiempo se deben aprovechar las actividades para llegar al dialogo, transmitiéndole al niño seguridad y desinhibiéndolo al momento de expresarse verbalmente. El maestro debe ser en consecuencia, un modelo en cuanto a su capacidad de expresión linguiística y utilizar palabras claras sin infantilizarlas.

Según la reforma educativa actual, en Venezuela se pretende crear individuos con capacidad crítica, reflexiva y analítica que fortalezca el avance científico y tecnológico nacional, 
orientando con prioridad el mejoramiento cultural y de la calidad de la vida de la población, a la participación en la búsqueda de alternativas de solución a los problemas y al progreso social y económico del país; y también estimularlo a la curiosidad para observar y explorar el medio natural, familiar y social.

Sin embargo, Bersntein (2002) sostiene que el discurso del maestro participa obviamente en la reproducción de muchas formas de dominación, discriminación y desigualdad, como la clase, edad, nacionalidad, religión, idioma, orientación sexual, dentro del currículo oculto.

Bernstein (2002), nos dice que la estructura social genera formas o códigos lingüísticos diferentes, esos códigos transmiten esencialmente la cultura y por lo tanto producen una conducta. O sea, nos viene a decir que el sistema de clases actúa sobre la estructura de la comunicación en todo el proceso de socialización.

De allí que, el discurso Pedagógico para Berstein (2002), es una modalidad de comunicación especializada "mediante la cual la transmisión / adquisición (aprendizaje) se ve afectada", en ese sentido, el discurso pedagógico es un medio de recontextualizar o reformular un discurso primario. La recontextualización se manifiesta en la significación. Parafraseando a Berstein (2002), decimos que el discurso pedagógico "no es una gramática para especializar un discurso específico sino un principio de desubicación, reubicación y reenfoque de otros discursos especializados, que los pone en una nueva relación recíproca e introduce un nuevo ordenamiento interno temporal". De esta forma la regla fundamental del discurso pedagógico es la recontextualización a través de dos órdenes constitutivos: el discurso instruccional y discurso regulativo. El primero regula la transmisión de competencias y capacidades y el segundo regula la forma como se construyen un orden y una relación e identidad social.

De manera, que las prácticas discursivas del docente pueden develar la Ideología y poder del educador en el aula., un ejemplo de ello lo constituye la frase "A ver, todos a ponerse de pie", esto es tal vez el comienzo con que legitima su autoridad el docente cuando ingresa al salón de clases. Evidentemente la manera como llama la atención cuando alguien no se ha puesto de pie muestra su concepción de la educación. La dilucidación de la misma, nos conduce a averiguar ¿cuál es la ideología que subyace a la práctica discursiva del educador y los efectos en las concepciones de futuros posibles, cogniciones y socializaciones variadas de los niños o adolescentes?

A tal efecto, las formas en que las ideologías se expresan y reproducen los educadores en el discurso suponen averiguar el estatuto y funciones mentales de "sus" ideologías en términos de cognición social. Las condiciones y funciones de las ideologías en el aula no sólo son cognitivas sino también sociales, políticas, culturales e históricas. Sin lugar a dudas, las ideologías se forman, cambian y se reproducen en el discurso y la comunicación socialmente situados (Van Dijk: 2000). Ahora bien, la ideología se entiende como un conjunto de ideas y representaciones que se imponen a las personas como verdades absolutas, produciendo un autoengaño, una ocultación en su pensamiento y formas de actuar; la función de las ideologías en las aulas constituyen y modelan formas bajo las cuales los alumnos viven y construyen significativamente su realidad, sus emociones, sueños, intereses y otros. 
A este particular, las ideologías de los educadores muchas veces traducen una visión del mundo, una perspectiva de las cosas, de los acontecimientos y comportamientos; las mismas constituyen una construcción socio histórica por lo tanto, son relativas, parciales, incompletas y requieren de reelaboraciones continuas para evitar caer en los absolutismos que no permitan la reflexión y al contrario favorezcan la dominación.

La concepción del mundo que traduce la ideología dota a los educandos de un sentido de pertenencia e identidad, les hace conscientes de las posibilidades y limitaciones de sus actos.

Ante lo anteriormente expuesto, surge la necesidad de dar respuesta a las siguientes interrogantes:

- ¿Cómo son las prácticas discursivas que se desarrollan en el aula del sexto grado en San Juan de los Morros, Guárico Venezuela?

- ¿Cuáles aspectos ideológicos y de poder están implícitos en esas prácticas discursivas?

- ¿Cuáles son las manifestaciones de poder subyacentes en las expresiones gestuales del docente?

\section{Objetivos de la Investigación}

1. Conocer las prácticas discursivas que se desarrollan en el aula del sexto grado en San Juan de los Morros Guárico Venezuela.

2. Analizar los aspectos ideológicos y de poder que están implícitos en las prácticas discursivas y gestuales que se desarrollan en el aula del sexto en San Juan de los Morros Estado Guárico.

3. Develar las manifestaciones de poder subyacentes en las expresiones gestuales del docente.

Este estudio se considera relevante por cuanto el profundizar en las manifestaciones discursivas en el aula, inevitablemente nos conduce a darle una mirada al currículo oculto, es decir, a los aspectos de la vida cotidiana de las escuelas y de las aulas a los que se presta menos atención; o, el significado social y los efectos no previstos de las experiencias escolares en los que se ven envueltos educandos y educadores.

El currículo estático referido a los procesos de planificación y el currículo dinámico que tiene que ver con la explicitación de las intencionalidades en los centros educativos están condicionados por el currículo oculto, o dicho de otro modo por lo implícito que tienen que ver con las concepciones educativas de los docentes, su formación, las maneras como se conciben las intencionalidades del estado, las ideologías que subyacen a la práctica educadora, los intereses grupales, el estado emocional, entre otros y que están presentes en los procesos de enseñanza y de aprendizaje.

Así muchas veces el discurso oculto de las cotidianidades en las aulas traiciona las buenas intenciones de muchos educadores. Las ideologías así como el poder, los discursos o el uso del lenguaje, afectan de manera decisiva en los procesos de cognición y socialización de los niños. En las manifestaciones discursivas se observa que los educadores no consideran la lengua 
materna de los educandos, por consiguiente ni su cultura en las aulas. Existe un discurso discriminatorio y parcial, especialmente en la construcción de saberes que impone barreras arbitrarias e injustas; y la aceptación de esos discursos como válidos, correctos y normativos sin someterlos a una dilucidación crítica constituyen una discriminación que lleva consigo efectos negativos muy profundos en las futuras generaciones.

\section{Ideología y Poder}

El concepto de ideología es quizás uno de los conceptos más polémicos en el ámbito de las ciencias sociales. Este es un término acuñado inmediatamente de producirse la Revolución Francesas, en 1797. Su creador fue Destutt De Tracy, uno de los responsables del Instituto de Francia, entidad que tenía como misión difundir los ideales del Iluminismo. En su obra Elements ideología, escrita entre 1801 y 1815, propone la necesidad de una nueva ciencia de las ideas, una "ideología", que sería base de todas las demás ciencias. La necesidad de este nuevo concepto corre parejo a la de explicar la forma como se construyen nuestras ideas. Frente a concepciones innatitas de las ideas como la de la religión, principalmente, venía defendiendo, ahora el concepto ideología se proponía facilitar otra clase de explicaciones de corte no determinista.

A decir en palabras de De Tracy, nuestras ideas están basadas en sensaciones físicas, por lo que pueden ser estudiadas de manera empírica con los métodos propios de la ciencia, con lo cual los sesgos y prejuicios podrían ser eliminados. Mediante la investigación es cómo podemos llegar a saber que esas ideas tienen un origen en las necesidades y deseos del ser humano. Esas necesidades y, en consecuencia, esas ideas deberán constituir el fundamento de la estructura de las leyes reguladoras de la sociedad.

Aunque en un principio el propio Napoleón aparece como patrocinador de este Instituto de Francia, pronto se desmarca de él y considera de manera peyorativa esta nueva ciencia de la ideología. Así, por ejemplo, no dudará en culpar a la ideología de su retirada rusa. Los ideólogos, según Napoleón, son todos aquello intelectuales que no avalan sus planes políticos y que carecen de sentido realista y práctico; en el fondo, ideología son las opiniones que defienden los adversarios.

La filosofía alemana se va a dedicar también a profundizar ampliamente en este concepto. Georg Wilhelm Friedrich Hegel, explica como las ideas dominantes en una determinada época son relativas, en cuanto dependen de situaciones históricas y, como éstas, están sujetas a modificaciones. Karl Marx, como discípulo de Hegel, va a poner un especial énfasis en demostrar que las ideas sociales y políticas se transforman dependiendo de las dinámicas que promueven las relaciones entre las clases sociales de cada sociedad. En nuestro siglo, diversos fenómenos históricos van a ser utilizados para favorecer un descrédito de este concepto, especialmente el genocidio y la destrucción a que dio origen el movimiento nazi, las ideologías fascistas italiana y española, los excesos del estalinismo, ciertas características de los partidos comunistas de los países del Este, etc. de alguna forma que quiso asociar el término ideología con la irracionalidad y el dogmatismo que acompañaba a los fenómenos que acabamos de citar.

De ahí que incluso algunos pensadores, curiosamente de corte muy conservador, llegasen a hablar del "final de las ideologías". 
Si por ideología se entiende el conjunto de ideas y de representaciones que se imponen a las personas como verdades absolutas, produciendo un autoengaño, una ocultación en su pensamiento y formas de actuar, es claro que esta concepción negativa de las ideologías, sino está muerta ya, debería estarlo. Por lo tanto, la función de la ideología en la sociedad humana se concentra principalmente en la constitución y modelado de formas bajo las cuales las personas viven y construyen significativamente su realidad, sus sueños, deseos y aspiraciones.

Las ideologías siguiendo a Therborn (1997, pp 15 - 16), someten y cualifican a los sujetos diciéndoles haciéndoles reconocer y relacionándolos con:

1. Lo que existe, y su corolario, lo que no existe; es decir, contribuyen a hacernos conscientes de la idea de quiénes somos, qué es el mundo y cómo es la naturaleza, la sociedad, los hombres y las mujeres.

2. Lo que es bueno, correcto, justo, hermoso, atractivo, agradable, así como todos sus contrarios. Esto ayuda, por consiguiente, a la normalización de nuestros deseos y aspiraciones.

3. Lo que es posible e imposible. Conociendo ambas dimensiones definimos las posibilidades y sentido del cambio, así como sus consecuencias. Nuestras esperanzas, ambiciones y temores quedan así contenidos dentro de los límites de las posibilidades concebibles.

El discurso del mantenimiento de una sociedad, de defensa del orden establecido juega, por tanto, con estas tres dimensiones del proceso ideológico. En función de ellas, los intelectuales orgánicos al servicio de un determinado modelo social pueden elaborar diversas modalidades de discurso:

A. En primer lugar pueden concentrarse en subrayar únicamente las parcelas o rasgos existentes de aquella realidad que refuerza los intereses del poder dominante; o bien pueden dedicarse a negar lo existente, por ejemplo, tratando de convencer a sus destinatarios de que no existe la pobreza, la enfermedad, o que la lucha de clases es ya algo irreal, o, circunscribiéndonos al terreno educativo, que no hay fracaso escolar o que no existen otras asignaturas, ni contenidos, ni metodologías de enseñanza-aprendizaje diferentes de las ofertadas por una institución escolar concreta, etc.

B. Dado que, en muchas ocasiones, la realidad es difícil de ocultar, se puede optar por una segunda vía, la de disfrazar esa realidad "negativa" etiquetándola de tal forma que proporcione alguna razón explicativa en la que la culpa sea únicamente de esa misma realidad. Así, por ejemplo, se llega a explicar que los obreros trabajan donde trabajan, y viven dónde y cómo viven porque en su juventud fueron unos vagos y vividores; o que los alumnos, debido a su falta de atención o a que son charlatanes impenitentes, fracasan en la escuela o en una determinada área de conocimiento y experiencia. En esta modalidad discursiva son siempre los propios obreros, alumnos, etc., considerados individualmente, los únicos responsables de su destino.

C. Pero también en muchas ocasiones la existencia de injusticias, de situaciones discriminatorias, puede ser prácticamente imposible de ocultar. En una coyuntura similar, una tercera opción consiste en defender la imposibilidad de actuar de forma 
diferente, la imposibilidad de un cambio distinto al proyectado, o en tratar de convencer a esa sociedad de que por el momento no es posible modificar ese estado de cosas, en un intento de aparcar la solución de tales injusticias para un futuro que siempre será futuro. Por ejemplo, justificar la dificultad de transformar las leyes sobre el apartheid en Sudáfrica, porque eso significa violar el derecho constitucional, por lo que es necesario introducir antes otros cambios, practicando así una política de permanente dilación. O, situándonos de nuevo en el ámbito educativo, manifestando, por ejemplo, que no es posible atender a las demandas de equiparación salarial de los profesores con el resto de funcionarios de la Administración, porque hay que realizar los estudios convenientes acerca de su posibilidad, o porque detrás de los profesores vendrán otros colectivos solicitando mejoras, o sobre la base de que el Estado no tiene tanto dinero, etc.

La ideología traduce, desde nuestro punto de vista, una visión del mundo, una perspectiva sobre las cosas, acontecimientos y comportamientos, pero siendo al mismo tiempo conscientes de que esta concepción del mundo es una construcción sociohistórica y que, por consiguiente, es relativa, parcial y necesita una reelaboración permanente, para evitar caer en absolutismo que impida la reflexión y favorezca la dominación de los hombres y mujeres. Esta concepción del mundo que traduce la ideología dota a los ciudadanos y las ciudadanas que la comparten en un sentido de pertenencia e identidad, les hace conscientes de las posibilidades y limitaciones de sus actos, estructura y normaliza sus deseos y, al mismo tiempo, proporciona una explicación de las transformaciones y de las consecuencias de los cambios. La ideología implica asunciones sobre el propio ser individual y su relación con otros colectivos humanos y con la sociedad en general.

Este significado del concepto de ideología permite "la creación de estructuras compartidas de interpretación, valor y significación" (Kemmis, S., 1998, P. 116), que en el caso de no ser conscientes de su relativismo, de la relación dialéctica entre la conciencia individual y las estructuras sociales, pueden funcionar como cosmovisiones creadoras de conductas irracionales y promotoras de alineación. Esto significa que cada ideología puede llegar incluso a crear entre los miembros que la comparten una especie de "sentido común" que, a su vez, tiene una traslación a la práctica a través de sus comportamientos individuales o colectivos.

En este orden de ideas, Gramsci (2007), utiliza el concepto de hegemonía ideológica para profundizar en este último matiz; para comprender la unidad existente en toda formación social concreta. Éste considera que la ideología dominante en una situación histórica y social puede llegar a organizar las rutinas y significados del llamado "sentido común". Lo que quiere decir que esa ideología impone a sus seguidores unos significados y posibilidades de acción de manera sutil, de tal modo que incluso formas de organización y de actuación de una sociedad que contribuyen a mantener situaciones de injusticia, llegan a ser percibidas como inevitables, naturales, sin posibilidad de modificación.

De manera tal que, de acuerdo a esta concepción, las ideologías no son algo estático o permanente, ni tampoco funcionan de una manera automática, mecánica, sin ningún tipo de fisuras. Establecer que las ideologías actúan homogéneamente, no es sino una forma de escapismo y fatalismo en la que éstas se nos presentan como elaboradas por una serie de seres superhumanos o mentes terrestres muy privilegiadas y que nos ofrecen a los demás seres 
inferiores para que los examinemos, aceptemos o rechacemos como si de un ofrecimiento de venta se tratase.

Un repaso a cualquier historia de la ciencia y de la cultura nos posibilita saber, en seguida, que las ideologías funcionan en realidad un tanto "desordenadamente". A tal efecto, averiguar cómo trabajan las ideologías en una determinada sociedad y en un momento histórico concreto requiere contemplarlas como "procesos sociales en curso" (Therborn, 1997, p. 63). El estudio de las formas de actuación ideológicas, al ofrecernos distinta información acerca de cómo es y de qué forma funciona el mundo en el que nos desenvolvemos, quiénes, por qué y cómo somos, en qué grado y en qué manera podemos transformar la realidad, etc., podrá revelar la existencia de diversos modos alternativos de comprender y actuar; así como también brindarnos la comprensión de los enfrentamientos producidos entre ellas cuando sus diferencias son más o menos grandes.

La ideología que, en un momento histórico concretó, funciona como hegemonía, gradualmente va a ser reformulada o sustituida mediante la confrontación entre otras tradiciones intelectuales diferentes, los intelectuales orgánicos y la praxis de las fuerzas sociales ascendentes. La confrontación entre ideologías es, por consiguiente, una realidad, pero, a su vez, cada una sufre transformaciones en algún grado en la medida que entre ellas coexisten, compiten y se enfrentan; del mismo modo, también van a superponerse, influirse y contaminarse unas a otras, en especial en las sociedades abiertas y complejas de nuestros días como subraya.

Therborn (1997), "una ideología de clase sólo existe en una pureza autosuficiente como construcción ana lítica y, en forma elaborada, quizás como texto doctrinal“(P. 65). El hecho de que las sociedades se caractericen por una determinada ideología predominante, una hegemonía ideológica, está manifestando el resultado de toda una serie de batallas libradas entre las diferentes clases o grupos sociales en momentos cruciales de crisis y contradicción. Su reproducción subsiguiente será fruto, en primer lugar, de la adecuada reproducción de tal ideología mediante discursos textuales y simbólicos, protegidos a su vez con todo un conjunto organizado de enunciados, proposiciones, clasificaciones, reglas y métodos que tratan de impedir posibles desviaciones, y, en segundo lugar, de sus prácticas y formas no discursivas coherentes con lo anterior.

\section{Fundamentación Epistémica Y Metodológica}

\section{Fundamentos Epistemológicos}

La presente investigación se desarrolló en dos etapas; la primera tuvo una naturaleza teórica dado que su inicio estuvo referido a la indagación teórica por parte de las autoras de la misma, con el fin de conocer los supuestos teóricos de las prácticas discursivas y la ideología del docente desde su praxis pedagógica. Asimismo, con el fin de ampliar la perspectiva metodológica, así como también profundizar el conocimiento del objeto de estudio en otros contextos, la segunda etapa fue la empírica, y tuvo como escenario un Colegio de San Juan de los Morros Estado Guárico Venezuela donde se efectuaron varias observaciones al $6^{\circ}$ grado de dicha institución. Finalizado este proceso se procedió a la estructura final de la investigación mediante la interpretación de la información obtenida. 
A tal efecto, la era multidisciplinaria y comunicacional en que hoy se vive ha promovido un constante y dinámico cambio en las ciencias humanas o sociales, con las consecuentes variaciones en lo epistemológico y en lo epistémico; Distinguiéndose, según Martínez (2007), una metodología cualitativa, la cual debe ser descriptiva, inductiva, fenomenológica, holística, ecológica, estructural-sistémica, de diseño flexible y eminentemente humanista; Que conlleve a producir conocimiento con base en el contexto, la función y el significado de los actos humanos, rechazando la cuantificación de las realidades.

Según esta afirmación la epistemología post positivista, en la cual se fundamenta la investigación con enfoque cualitativo, destaca la necesidad de interpretar los hechos, y producir propio ambiente natural en que ocurren, con el significado que ellos tienen para quienes los viven, permitiendo mostrar la descripción de los resultados en toda su extensión y veracidad. Esta nueva visión paradigmática estableció una diferencia gnoseológica en la teoría del conocimiento superó el concepto de la realidad, vista como el "simple reflejo de las "cosas reales" percibidas y el conocimiento como copia de esa realidad", dando paso a la concepción del conocimiento como el "producto o fruto de una interacción, de una dialéctica, o diálogo, entre el conocedor y el objeto conocido” (Martínez, 2007, p.25) señaló:

La realidad concreta es algo más que los hechos o datos formados, más o menos, en sí mismos. Ella es todos esos hechos, y todos esos datos, formados en sí mismo. Ella es todos esos hechos y todos esos datos, más la percepción que de ellos está teniendo la población en ellos envuelta. Así, la realidad concreta se presenta a mí en la realidad dialéctica entre la subjetividad y la objetividad.

El trabajo cualitativo a realizar permitió construir el objeto de la investigación (conocimiento de una realidad) bajo la permisa para las investigadoras, de la subyacencia de supuestos teóricos relacionados en una concepción general de la cultura propia de la población humana seleccionada que se investigó en San Juan de los Morros, Estado Guárico, Venezuela. En tal sentido, se describió lo que se encontró detrás del accionar social, por lo que todo cuanto fue considerado de carácter fenomenológico (Leal, 2008), se estudió asimismo los significados que los hechos y circunstancias surgieron desde el punto de vista de las investigadoras.

\section{El Método}

La presente investigación se sustentó bajo la tendencia del enfoque Cualitativo con paradigma Post-positivista, ya que se le da importancia al conocimiento de la propia experiencia humana, a la subjetividad como fuente de entendimiento y el relato de los distintos actores, que sirven de punto de referencia para construir el conocimiento social y la historia misma lo cual constituye el objeto del estudio.

A propósito de esto, Maldonado (2000) señala que la investigación cualitativa: Es un conjunto de descripciones analíticas de escenarios culturales, situaciones, eventos, personas e interacciones personales, recreando lo que sienten y piensan los participantes, ya sea de manera explícita o implícita, a fin de estudiar la vida humana donde ella naturalmente ocurre. (p. 3). 
Cabe destacar, que en una investigación con parámetros cualitativos el investigador es el principal instrumento de recolección de datos, trascripción, análisis e interpretación. En consecuencia, se enfatiza la importancia del investigador en relación a sus aspectos éticos morales y básicos. Por su parte, Martínez (2012) al hacer referencia a las ciencias humanas, plantea que "...estas están rodeadas de una realidad muy compleja para tratar de explicarlo de manera analítica-mecanicista" (p.76).

Según Martínez (2007), la realidad es tan complicada, que es conveniente conocer la misma bajo una visión holística, lo que permitiría ver el fenómeno de una manera total, integradora, en constante interacción, de modo que la tendencia cuantitativa limitaría, este conocimiento, pues al estudiar la realidad, tiende a separar y aislar todos sus aspectos.

A tal efecto, a continuación se especifican los supuestos filosóficos que dirigen la investigación.

Epistemología, el episteme básicamente se entiende como conocimiento; la epistemología por su parte, es la ciencia que se encarga de estudiar la manera de acceder científicamente al conocimiento; es decir, es la ciencia filosófica que permite generar y validar nociones que a través de estudios rigurosos se convierten en teorías validas científicamente en el abordaje y producción o confirmación de conocimientos. En tal sentido, la ciencia desde la perspectiva cualitativa surge de la subjetividad e involucración entre el sujeto y el objeto.

Ontología, se refiere a la esencia del objeto en su contexto. Para efectos de este estudio, el aula de clase se concibe como un espacio de comunicación, entendimiento, participación, y comprensión, donde cada experiencia es importante para el éxito del proceso de enseñanza y aprendizaje.

Gnoseología, constituido porque el conocimiento que se genera entre los sujetos implicados (informantes clave), se da importancia a la relación que tiene existe entre ellos y con el entorno. En este caso, la relación fue sujeto- objeto involucrados y se considera de importancia el entorno. A este particular, el conocimiento surge de la dialéctica entre ambos.

Axiología, se consideran los valores, que emergen de las vivencias del de los sujetos inmersos en esta investigación en su sentir cotidiano, en las relaciones interpersonales con su mundo de vida, tales como, la comunicación, el respeto, la cooperación, la ayuda mutua, la equidad, entre otros

Teleológico, los ejes que direccionan esta investigación lo constituyen los diferentes objetivos de la presente investigación

\section{Informantes Clave}

En esta investigación participaron como informantes un docente y cinco alumnos de sexto grado de la Unidad Educativa ubicada en San Juan de los Morros, Estado Guárico, Venezuela". Cada informante fue seleccionado en atención a su disposición favorable a colaborar con la investigación y sus identidades serán resguardadas, para lo cual se empleó pseudónimos. 


\section{Técnicas e Instrumentos Empleados en la Investigación}

De acuerdo al tipo de investigación con enfoque cualitativo, los procedimientos técnicos e instrumentos de recolección de datos utilizados fueron orientados y diseñados para permitir acceder a la información y obtenerla directamente de los informantes seleccionados. Las técnicas de observación participativa, las notas de campo constituyeron la base fundamental para obtener la información.

En este orden de ideas, los aspectos observados fueron registrados en bitácoras diarias que posteriormente fueron interpretadas por parte de las investigadoras. De allí que las notas de campo representaron el pilar fundamental en el registro de las prácticas discursivas, los datos significativos concretos y los situacionales, con lo cual se logró reflejar lo que se observó y se escuchó en el transcurso de la investigación.

\section{Triangulación}

Según Taylor y Bodgan (1990) la triangulación consiste en "la combinación, en un estudio único, de los distintos métodos o fuentes de datos". Basado en ello se realizó la triangulación, combinando los contenidos de las notas de campo, los registros, las entrevistas y todos los documentos y fuentes de datos pertinentes al problema investigado. Con esto se logró la comprensión clara y precisa de las opiniones y juicios emitidos por las personas estudiadas, apreciándose de manera detallada la situación en cuanto a los distintos escenarios y aspectos observados.

\section{Técnicas de Interpretación.}

El proceso de interpretación no constituyó una etapa precisa o temporalmente determinada en el proceso de la investigación, por el contrario fue ocurrente a la recogida de datos y su categorización. Sobre ellos se trabajó en forma exhaustiva.

Los datos a obtener a través de los diferentes instrumentos a aplicar fueron llevados a textos escritos textualmente, dividiéndolos o segmentándolos en unidades significativas, conectándolos aspectos más específicos mediante la interpretación y el proceso reflexivo.

\section{Interpretación de la Información}

Según Martínez (2012) la categorización consiste en, categorizar o clasificar las partes en relación con el todo, de describir categorías o clases significantes de ir constantemente diseñado, rediseñado, integrando, reintegrando el todo y las partes a medida que se revisa el material y va emergiendo el significado de cada sector, evento, hecho o dato

\section{Resultados del Proceso de Observación. Categoría: Gestual.}

\begin{tabular}{|l|c|}
\hline Unidad de Observación & Lo Observado \\
\hline & \\
\hline
\end{tabular}




\begin{tabular}{|l|ll|}
\hline & - & Cruzamiento de brazos. \\
& - & Parada detrás del escritorio \\
GESTUAL DEL DOCENTE & - & Contacto ocular pronunciado \\
& - & Ojos entrecerrados \\
& - & Brazos en "jarra" \\
& - & Piernas ligeramente separadas \\
& - & Giros de inspección con la cabeza \\
& - & Señalamiento con los dedos \\
& - & Desplazamiento constante en el aula. \\
& & Expresión de seriedad en el rostro. \\
\hline
\end{tabular}

\section{Cuadro 1}

La gestual del docente (comunicación no verbal) prácticamente características ritualistas enfatizadas por el hecho de que periódicamente las repiten. Así en el proceso de observación se detectó que el maestro inicia cada clase apelando a un gesto característico de autoridad, como por ejemplo, cruzar los brazos, pararse detrás del escritorio, permanecer totalmente impasible detrás del escritorio. Caminar con ímpetu y desafiante hacia los alumnos. El contacto ocular se hace muy pronunciado.

En su intento por proyectar una cierta conducta grave, enfatizar su papel de autoridad y fortalecer su terrible presencia, los maestros permanecen inmóviles ante el grupo. En ocasiones, un aire de aflicción cruza su frente como si tratasen de aparecer como nobles y desinteresadas víctimas. Con ojos entrecerrados, los brazos en "jarra” y las piernas ligeramente separadas para causar la impresión de un cuerpo firmemente equilibrado, capaz de repeler y luchar contra los intentos de subversión, los maestros giran la cabeza de un modo firme, muy parecido a la cámara de vigilancia de las tiendas departamentales. Esta postura autocorriente y mecánica tiende a reforzar el aspecto de seriedad de la ocasión y contribuye al engrandecimiento artificial del maestro como un ser in abominable, impenetrable y todo poderoso.

El maestro se va reduciendo a la calidad de jefe absoluto, y el conocimiento es trasmitido mecánicamente.

Abundan las palmadas para llamar la atención y los golpes sobre el escritorio, sin embargo, son escasos los gestos de aprobación y afectividad hacia el alumnado. El contacto corporal docente-alumno es muy limitado. El maestro se mantiene distante.

\section{Resultados Del Procesos De Observación Categoría: El Discurso.}




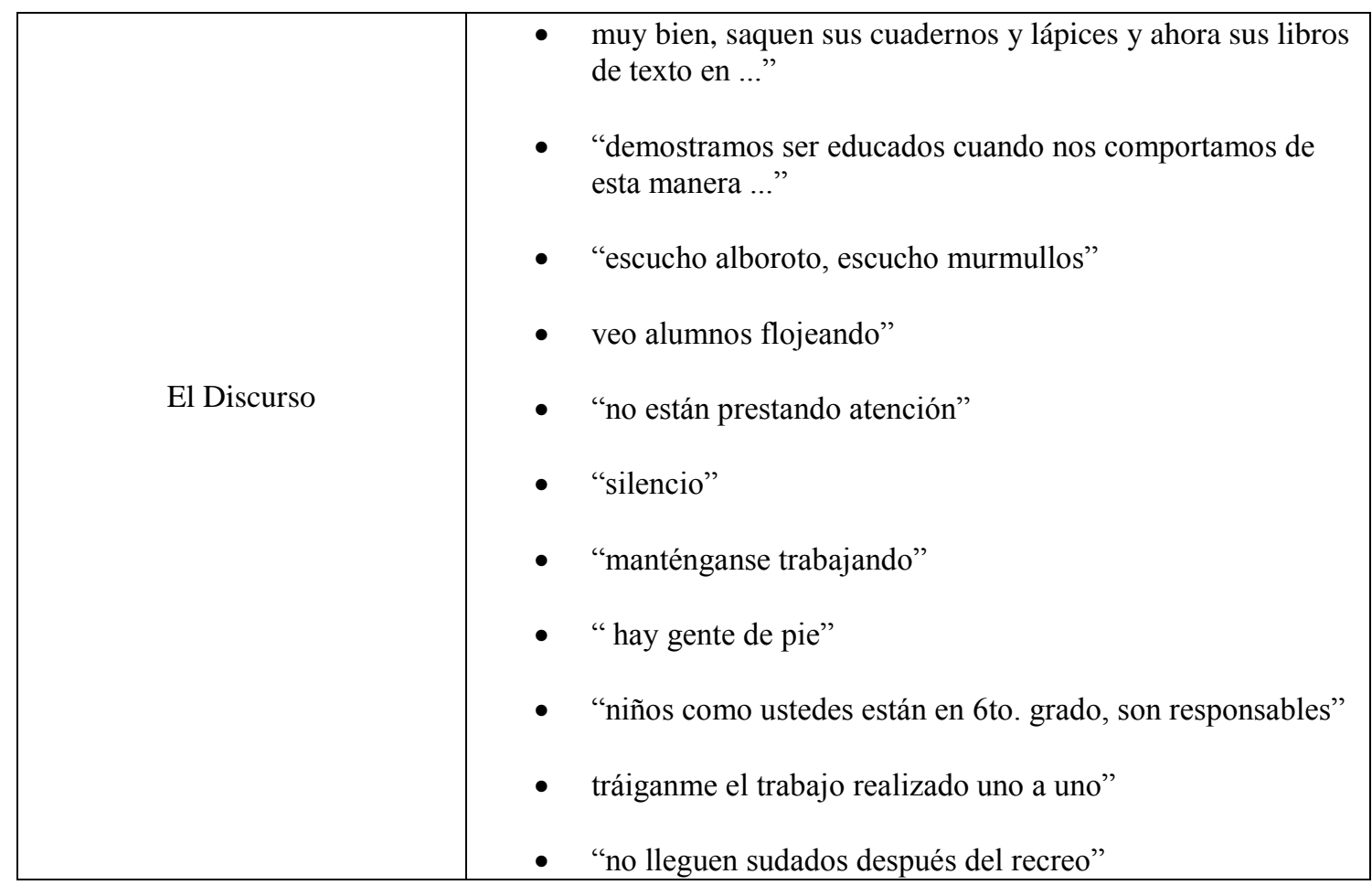

Cuadro 2

El discurso adquiere forma de monólogo exasperante y es empleado por el maestro para definir la situación o el contexto de la institución. Ocasionalmente, el contexto es tan ambiguo que debe ser definido en repetidas ocasiones por el docente, de modo que los estudiantes sepan exactamente lo que se espera de ellos.

El discurso del maestro hace uso de declaraciones y proclamas que algunas veces son denominados "performance". Un performance en términos de McLaren (1995) es un acto o discurso que da el ser a un estado convencional de cosas. Por ejemplo, cuando una maestra decía algo como "niños como ustedes están en 6to grado son responsables", con ello no sólo mostraba un estado de cosas, sino que realmente daba vida a ese estado de cosas. Además de los performance, los maestros empleaban formas verbales indirectas como "hay gente de pie", "escucho alboroto", "escucho murmullo", "veo alumnos flojeando", "no están prestando atención" es una forma indirecta de ejercer el poder a través del discurso.

El discurso también permite que los maestros establezcan la escala o la frecuencia de las respuestas en los estudiantes. Si se presume que un estudiante no sigue las instrucciones, el maestro puede solicitar que presente alguna evidencia de que entendió los procedimientos. La falta de tal testimonio puede resultar en una reprimenda severa o en una amonestación.

Manténganse trabajando, es una frase que constantemente emplea el docente. Enfrascarse en el trabajo constituye como un estado de gracia. Si por el contrario los alumnos se involucran en algún juego, son amonestados y castigados. Los infractores y transgresores se vuelven “contaminadores" del sagrado lugar de trabajo. Esto deja ver claramente que en el aula está la manipulación del poder por el poder mismo. El ejercicio conspicuo del poder ocurre generalmente cuando los estudiantes ejercen acciones que no responden a las prioridades y 
planes de los maestros. Por ejemplo, si un estudiante tiene que ir al baño, el docente responde generalmente no, cuando claramente no existe razón para negar el permiso, excepto por un inapropiado y gratuito ejercicio del poder por parte del docente. Otro ejemplo es cuando los estudiantes son incesantemente exhortados a mantenerse ocupados en una tarea específica, la exhortación adoptada por lo general la forma de una proposición sagrada, más que la de una técnica reconocida de manejo, diseñada para ayudar al maestro a sobrevivir, hay pocas oportunidades para que el estudiante interprete el significado de estar ocupados o el valor de las tareas asignadas.

\section{Reflexiones}

La existencia en el aula es vivida dentro de una multiplicidad y pluralidad de discursos cambiantes, anclados material y simbólicamente en rituales tanto gestuales como orales a través de los cuales el maestro manifiesta su autoridad y poder. En el aula diversos discursos luchan por el dominio, y el docente tiene el cometido de privilegiar interpretaciones particulares de cómo debería ser entendida y enfrentada la vida cotidiana.

Las clases observadas tenían poder rituales mediante una serie de postulados y directrices que parecían incuestionables. La mayor parte se enseñaba verbalmente, y gran parte del contenido difundido por los docentes no era susceptible de verificación, pero tampoco era vulnerable a la falsificación. A pesar de la monótona repetición, la invariación y la formalidad de la institución en el aula, casi todos los estudiantes se adaptaban a lo que se referían de ello, si bien su conformismo no implicaba en la mayoría de los casos, el conocimiento. En tanto que el conformismo no necesariamente entrañaba la creencia de los estudiantes en los valores de la escuela, servía como índice de la aceptación de dichos valores y de un ajustarse a los códigos y convenciones culturalmente postulados en la escuela.

El discurso, es una configuración cultural y política de significadores, mediante la cual se inscriben las ideologías. El discurso deviene en la generalidad de los casos en un monólogo exasperante, y el docente tiende a acompañarlo de toda una gestualística ritualisticamente concebida para definir quién tiene la autoridad y el poder en el aula. De esta manera el salón de clase se convierte en campo Homérico de batalla donde se libran constantemente luchas en torno a las relaciones existentes de poder.

\section{Bibliografía}

Berstein, D (2002) La Educación de la Comunicación. Madrid: Editorial Alianza.

Denis, J. Y Gutiérrez (1993) Las Competencias Lingüísticas. Ediciones Gramática, S. A. México.

Destutt De Tracy (1801). Elements ideología. Instituto de Francia.

Gramsci, A. (2013). Escritos sobre el lenguaje. Buenos Aires: Eduntref

Hernández, S.; Fernández, C.; y Baptista, L. (2007). Metodología de la Investigación. México: Mc Graw Hill Interamericana. 
Hurtado, I. y Toro, J. (2001). Paradigmas y Métodos de Investigación en tiempos de cambio. Valencia, Venezuela: Episteme.

Kemmis, S. \& Mctaggart, R. (1988). Cómo planificar la investigación-acción, Barcelona: Laertes.

Leal, J. (2008). Autonomía del Sujeto Investigador. Mérida: Universidad de los Andes.

McLaren, P. (1995). La escuela como un performance ritual: hacia una economía política de los símbolos y gestos educativos. Buenos Aires: Siglo Veintiuno Editores S.A.

Maldonado, J. (2000). El paradigma cualitativo en la investigación educacional. Maracay: Fortaleza.

Martínez, M. (2006). Ciencia y arte en la metodología cualitativa. México: Trillas.

Martínez, M. (2007). El paradigma Emergente. México: Trillas.

Martínez, M. (2012). Ciencia y arte en la Metodología Cualitativa. México: Trillas.

Moreno, M (1999). La Pedagogía Operatoria. Barcelona España. Ediciones Laia.

Pérez, J. (2000). Medición del Plan Lector y su Relación con la Comprensión Lectora de los Alumnos de 3er Grado de la Escuela Básica del Sector Escolar No. 2 de Tinaco. Estado Cojedes. Trabajo de Grado de Maestría. Universidad Bicentenaria de Aragua. Maracay-

Rivas, C (2001) Un Nuevo Paradigma para la Educación en Venezuela. Cuadernos Lagoven. Caracas.

Rodríguez, I (2000). La Reforma Curricular Leída desde la Educación Popular. Publicado en Movimiento Pedagógico (Maracaibo- Venezuela).

Taylor, S. J. y R. Bodgan (1990). Introducción a los métodos Cualitativos de Investigación. Paidós: Buenos Aires

Therborn, G. (1997). La ideología del poder y el poder de la ideología. Madrid España: Siglo Veintiuno Editores.

Van, D (2000) La Construcción de Discurso Oral. Madrid: Edición Morota.

Woods, R. (1999) Estrategias Didácticas para mejorar la comunicación Oral. Narcea, S.A. Madrid. 